\title{
Maximizing Digital Transformation Innovation - Design Thinking
}

\author{
Satish Kumar Boguda ${ }^{1}$ \\ Software Engineer - Product Owner, Data Scientist, \\ Scrum Master, California -USA
}

\author{
Arsid Shailaja ${ }^{2}$ \\ Information Technology Manager \\ Hyderabad - India
}

\begin{abstract}
Regardless of whether it is a large organization, for example Walmart or a small-scale retailer of automotive parts, a company's performance is measured by its profitability ratio over a key focus on investment strategies that drives the best value for Return on Investment - ROI, and that is estimated using some of the key accomplishments which include cost reduction, production efficiency, risk minimization, improved performance of process metrics and great customer experience. Perhaps the most critical resources in business today are people, processes and technology. These days, in pretty much every industry, the customer journey is driven by digital consumers with the ability to process the mission critical business information in real time that helps organizations to serve more efficiently and provide seamless customer experience. Moreover, with the evolution of technological advances, organizations need to transform to address rapidly changing business landscapes, which is the main reason why digital transformation is so crucial for companies that enables to redefine the complex business process into simple and innovative solutions that helps business executives focus more on business results, innovation and continuous development. The main focus of this paper is on how design thinking redefines business performance by generating innovative ideas and providing sustainable, groundbreaking customer-centered solutions by glancing through the viewpoint of user needs.
\end{abstract}

Keywords-Design Thinking, Digital Transformation, Industrial Revolution, Edge Computing, Artifical Intelligence, Internet of Things, $5 G$ Network, Blockchain.

\section{TECHNOLOGY EVOLUTION - INNOVATION BEYOND IMAGINATION}

Technology is disruptive, it changes the way we connect, automates the way we work and socializes our way of interacting with people and today it's more connected than ever before. Throughout the last century, it has taken numerous shapes and sizes influencing pretty much every division of the economy, for example from the very first admiral American television model in $\underline{1948}$ to today's high dynamic range - HDR Quantum LEDs, from Motorola's first mobile telephone by "Martin Cooper" to the present Apple's carry anywhere iPhone, it is creating immersive experience by bridging the gap between the digital and physical world through communicating from all over the globe.

In his editorial "Donny Lamey" - DiscoverTec Chief Executive Officer (CEO) describes the advancement of technological developments and how mankind has been increasingly reliant on it for many generations, which is transforming human lives in each and every dimension, for example: right from disparate ancient man tribes to the worldwide web.

"Technology has forever changed the world we live in. We're online, in one way or another, all day long. Our phones and computers have become reflections of our personalities, our interests, and our identities. They hold much that is important to us." - James Comey.

Although most of us enjoy the benefits of the modern-day technology, the imagination to solve the complex problems leveraging technology was predicted during $15^{\text {th }}$ century, a way ahead of time by the artist, inventor and scientist named Leonardo da Vinci - a universal genius recognized as one of the greatest diverse human minds ever lived on this planet. His openness to innovation philosophies and conceptualized excellence was far beyond anybody's reach where he made numerous contributions to the scientific breakthroughs, including flying machines, parachutes, helicopters, military tanks, and so on.

"Some are born great, some achieve greatness, and some have greatness thrust upon them." - William Shakespeare

A fascinating article about "Vinci" on business insider from the author "Caralynn Lippo" which really got my attention to the famous predictions about the technology and modern world that are accurate today.

During the 18th century, the 1 st Industrial Revolution began where mankind began to increase productive capacity by automating his everyday routine tasks where mechanical development enables the use of machinery by powering through new sources of coal energy and steam power. The 2 nd Industrial Revolution was introduced in the 19th century wherein the division of manufacturing and mass production was introduced using the electric power which reshaped nations in many ways. Moreover, with massive technological advancement, almost every dimension of human life is simplified where anything can be accomplished in a fraction of seconds, thanks to mankind's one of the greatest technological innovations of all time, the "Internet," empowering billions of people across different geographical locations. Later in the 20th century, with the upswing of the 
early period of high-level robotics, the 3rd industrial revolution, also termed as the digital revolution began to take shape in which electronic devices, telecommunications and Information Technology systems boosted the efficiency of manufacturing processes. Presently we are exploring the possibilities of 4 th industrial revolution which is developed on the building blocks of the first 3 revolutions wherein the storm of technological advancements such as Artificial Intelligence, Edge Computing, Internet of Things, Augmented Reality, etc. are fundamentally changing sectors of the economy which deliver world-class customer experience by connecting through the digital and physical world.

From stone age to information age, practically, we are encircled by technological inventions at each and every moment of time and this is a game changer which plays a significant role in all areas of the business wherein it increases efficiency by saving time and money to generate more and more opportunities. Author "Chris Woodford" research from his article gives the historical timelines of technology right from the prehistoric age to the digital age of today.

Today we have turned into the focal point of our own reality wherein the technology of the future promise to shape the path for the world to overcome many of the environmental problems. Infact, almost every month a groundbreaking innovation is revealed with advancements going far beyond human genome intellectual ability which tends to leave many open questions about how and where we will go next? Is Artificial Intelligence the last invention of human civilization? What is the next big thing? Get ready for change, a new world is coming ...!!!

\section{DIGITAL REVOLUTION - THE FUTURE IS HERE}

The Internet has become a worldwide information hub, which is the fundamental paradigm shift behind the digital revolution, that has played a pivotal role in expanding the number of businesses through which companies make millions of profits today by adapting cutting-edge technology that provides unprecedented growth and opportunity building new business models. However, digitalization is not just about the modern technology, it is the way how innovation can be used quickly and efficiently which helps to reshape both electronic and engineering technology into digital world by bringing in new ways of communication or information sharing, that provides a 360-degree view of the customers.

"The Internet and digital technologies can and will boost economic, social, and political development, including by vastly expanding the capacity of individuals to enjoy their right to freedom of speech and expression, which is key to empowering human rights. " - Alexander De Croo.

Accelerated innovation in communication technology and the utilization of a wide scope of electronic devices in business has managed to make digital transformation possible. Presently, the grand total of text messages sent and collected every day surpasses the world's overall population. In his article, "Kenneth Burke' - the marketing director of Text Request describes how the worldwide use of text messages has managed to grow over the last decade. In addition, as per the "Internet World Stats" the overall number of internet users increased dramatically from "16 million users in December 1995 , that was 0.4 percent of the world's population to 4.39 billion users in March 2019, which is 56.8 percent of the total pollution."

Digital revolution is not the vision of the future, it is really happening right now with the interoperability of modern technology including the Internet of Things, Artificial Intelligence, Big Data Analytics, Blockchain, Edge Computing, 5G network etc. into all areas of the business that are fundamentally changing the operation of revenue models to bring value to its customers at whatever point and wherever they are. Fortune 500 companies are already investing millions of dollars in this huge revolution of digital transformation journey in order to sustain their business in a rapidly-paced ecosystem which provides the competitive edge over their competitors. Author "Tamara Rosin" elucidates in her article why digital transformation should always be perceived the highest priority for business executives and the various other factors that drive businesses to implement digital transformation. According to research conducted by the world's leading market research company researchandmarkets.com the digital transformation market is projected to increase from "USD 290.0 billion in 2018 to USD 665.0 billion by 2023, at a CAGR of 18.1 percent from 2018 to 2023."

For any industry, the biggest driving element of successful digital transformation lies in addressing the fundamental needs of client's business variations in real time and at the same time understanding that perhaps the journey of transformation goes well beyond technology alone, rather it comes with combination of redefining people, processes and policies which truly unleash the power of an organization. A survey conducted by McKinsey \& Company "a worldwide management consulting leader in qualitative and quantitative analysis," describes how industries can be transformed by taking into consideration the fundamental factors which really unlock excellence during the digital transformation journey. Furthermore, as the paradigm shift towards digital transformation is gaining momentum, multinationals are now progressively launching strategies to enforce digital skills and capabilities in order to accomplish an exceptionally focused digital innovation edge to expand the business profitability.

Over the past couple of years, a substantial number of great successes have begun to increase where some of the world's most prominent brands already are enjoying the benefits incredibly through the journey of successful business transformation by making an investment in digitalization. In the article published on digitalmarketinginstitue.com, the author showcases 5 successful storylines on how the digital transformation adventure was streamlined by world's leading companies such as SAP, DBS Bank, Hasbro, Pfizer and Subway. 
With the accelerating peaks and troughs of customer demands as well as a phenomenal number of organizations expanding on a continuous basis, the global trend "Digitalization" has great potential to transform companies, reinvigorate industries, design smart cities to transform millions of lives and strengthen the economic DNA of the nations through smart use of digital platforms and solutions.

The road to digital revolution has already created a path for technophiles in order to enter the world of business which truly characterizes the connection between mankind and technology to deliver amazing experience. Is your organization ready to digitally transform your business?

\section{BUSINESS CHALLENGES}

The unprecedented exploration of the globe is far advanced in the era of data where technological advances are discovering the digital world and creating a new ambitious goal for various organizations by attempting to simplify implementation and day-to-day operations.

"The Data-driven world will be always on, always tracking, always monitoring, always listening and always watching because it will be always learning" - Data Trends IDC

In a strategic competitive business world, one of the greatest challenge organizations face today is to keep-up with the pace of ever-changing business demands to generate real-time information by processing the enormous amount of data that is growing on a daily basis. Whether it is advanced industrial robotics or MRI scan or defense systems or level 5 autonomous vehicles, data is increasing exponentially, and this data explosion creates complex design challenges and ambiguities in terms of the pace of innovation in day to day business operations, hardware and software technology decisions as well as future proofing. Organizations have to invest a great deal of energy and cost to scale up their existing IT infrastructure landscapes having to adapt to the new paradigm shift of the advanced 21 st century technology approach that will bring significant benefits of adaptability, efficiency, usefulness of applications, interoperability and so on which generates higher profits to bring more value to the business by serving the customers in real-time across the globe and intelligently scaling to deal with the challenges of the next decade. According to research conducted by IDC Data Trends IDC the world's data explosion is growing from 33 Zettabytes in 2018 and will reach to 175 Zettabytes of data by 2025 which will be stored across various cloud data centers and data lakes. Moreover, with increasing demands of data being collected, managed and stored by organizations and various entities, it is extremely important for both organizations and individuals to safeguard their digital privacy in order to prevent hacking or inappropriate use of data. According to the survey conducted by "Javelin Strategy and Research," Javelinstrategy - Identity Fraud a leading global research-based advisory firm detected an 8 percent increase in identity theft in 2017 , which cost around 16.8 billion dollars in the US alone. However, improvements in the field of data management continue to evolve at the speed of light by integrating a wide spectrum of emerging technologies, such as Artificial Intelligence, Machine Learning, Blockchain, Lifecycle Management and Edge Computing platforms, that help various data-driven enterprises to inject intelligence into their business applications and customer life-cycle.

Furthermore, technological advances alone would not overcome these humungous data dilemmas whenever it comes to achieving business goals, it's all about the right combination of people trying to align the right set of technology to the key business process makes it possible for business to operate successfully.

\section{WAVE TO INNOVATION - DESIGN THINKING}

From Silicon Valley to Shenzhen - China, the biggest challenge for any commercial enterprise lies in delivering cost-effectively innovative products and solutions to its customers, and that comes only when you adapt the groundbreaking technologies from the wave of new innovation to expand beyond imagination. As the digital transformation journey starts with an innovative idea, which often tends to leave several open questions, including what the Return of Investment is - ROI, to what extent will the solution last in the competition, will regulatory and technological challenges have any impact in the upcoming years, what level of resources and procedures does it involves, and so on. All these questions can be addressed by working with relevant stakeholders by looking through the lens of universal language called "Design", which is the key work process.

"Most people make the mistake of thinking design is what it looks like. People think it's this veneer - that the designers are handed this box and told, "Make it look good!" That's not what we think design is. It's not just what it looks like and feels like. Design is how it works" - Steve Jobs

The intelligent technologies are already available; however, it is extremely important to have the right knowledge for which technology to adapt in solving the most critical business problem that drives the best value for the organization. The process of digital transformation is extremely challenging and there is always an increasing pressure for executives to innovate and create the digital business to deliver the real-time insights by predicting customer needs and adapt quickly. Design thinking isn't about the technology, it is all about how we use these technologies to tackle a business problem. The people-centric design thinking process, helps companies to bring together all the intelligent technologies for redefining customer experience by rethinking about Products and Services by placing the end user at the center of solving the business problem. Design is too important not just for designers alone. The 5 step Iterative process of Design Thinking empowers everybody to be part of creatively discovering the best solution. 
Empathize - In the process of delivering the right product and services to customers, Empathy fuels the connection between end users and design thinkers to understand the real business problems through the lens of customers pain points by leveraging observation, engagement and story-telling techniques.

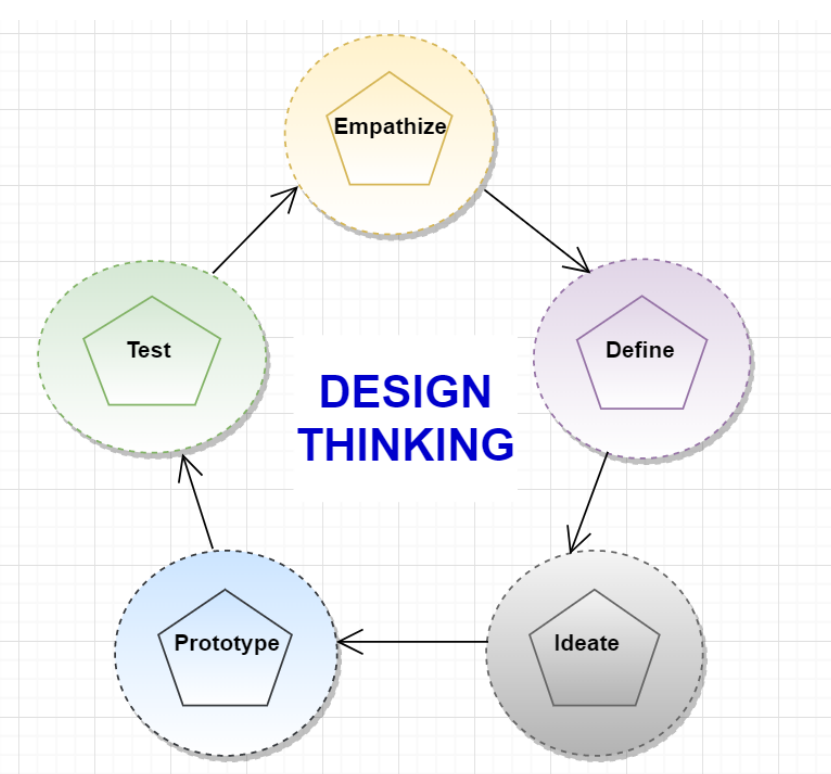

Define - In the design phase, the actual underlying business problem is determined based on the observations and information collected from the users during the empathize phase. Design thinkers classify and evaluate the identified problem in the broader perspective to gain insights and develop a plan to adjust the need for an innovative solution.

Ideate - In the ideate phase, the problem statement or market trends are addressed with a wide variety of brain storming techniques to come up with several innovative ideas which has the potential to address the business need and deliver better outcomes. The design thinkers work with different stakeholders on the basis of the ideas, conduct a fieldwork and gather feedback to shortlist the best solution and conclude the phase.

Prototype - During the prototype phase, the creative solution is implemented in line with the business case perception, ie: It can be anything from a low-fidelity design-board sketch to a high-fidelity tangible solution which can be later tested and get customer feedback accordingly.

Test - In this step, the design thinkers demonstrate the prototype solutions to the stakeholders and gather feedback to evaluate if the solution generates value to the business through tackling the actual business problem by addressing user challenges. Design Thinking is repetitive process in nature for example: if the solution sometimes doesn't resolve user needs, the process is repeated to go back to ideation and prototype phase until the genuine business needs are addressed.
As the demands of consumers change accordingly through the emergence of the digital disruption with a great potential for radical new commercial opportunities, business executives while addressing any business problem should focus on three key elements of the Design Thinking strategy that drives digital transformation innovation:

- Human Desirability

- Business Viability

- Technology Feasibility

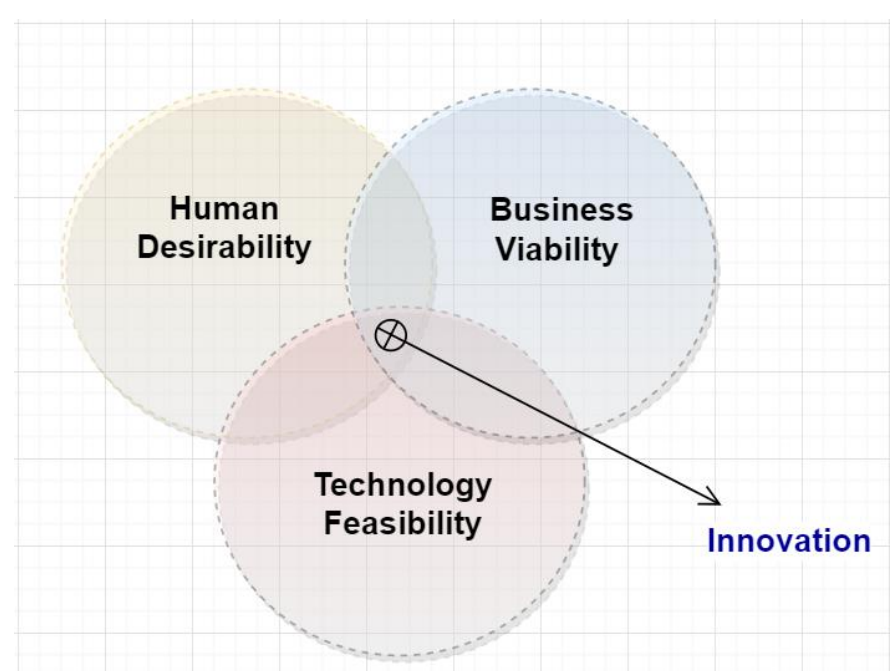

V. DESIGN THINKING IS THE ANSWER

Over a period of time, organizations need creativity to tackle the complex business challenges by breaking through technological innovations. Also, in the race of competition, every business wants to drive high in terms of creativity and groundbreaking value proposition and that happens only when we apply design thinking and it can be implemented to any business problem in any industrial sector which involves human interaction for example: be it a science invention, manufacturing process, change management procedures or when you are launching a new brand or product offering etc. to take your business to the next level. Moreover, it is extremely valuable for business pioneers to pinpoint what their visionary use case is and how it can be executed that generates the significant value in the global marketplace and then apply design thinking methodology which is more than a creative process that pulls an idea through the execution stage.

One of the famous quotes by Albert Einstein "We can't solve problems by using the same kind of thinking we used when we created them."

This human-centered design thinking process has already innovated numerous billion-dollar enterprises in so many ways, elsewhere here are some of the industry uses cases: 
- Airbnb's innovative transformation journey as described in firstround from a failed start-up to a billion-dollar business today that started with $\$ 200$ a week in 2009 to a projected revenue of $\$ 8.5$ billion by 2020 .

- Apple has delivered innovative products through a solution-oriented design thinking process, Design Thinking Apple making the company a great success through better customer satisfaction.

- SAP is redefining growth and profitability sap design thinking through the "SAP Leonardo" digital platform that rely completely on design thinking methodology.

- Netflix stays ahead of its competitors by following the design thinking process that helps them predict customer requirements in advance and provide them with the relevant services, all this is done through "Empathy."

- Adidas outperforms its competitors by embracing new business ideas which help them to remain competitive by offering a great customer experience.

- Ford a 115-year-old pioneer of American automakers, redefines its organization by implementing the innovative design thinking approach.

- This article describes about Doug Dietz story who led the breakthrough innovation of GE Healthcare - MRI transformation using the human centered design thinking process.

- UX manager of Home Depot Brooke Creef illustrates how design thinking drives innovation within their product teams to redefine business performance that address the customer's key needs, helping them stay on top in supply and demand.

- $\quad \underline{\text { PepsiCo }}$ turned design thinking into their strategic approach to anticipate their consumer demands and transform the products accordingly to increase business innovation as a whole.

- Delta Airlines emphasizes innovation by implementing a customer-centric design thinking process to understand the real travel needs of customers.

In the wave of enrichment, technology is being implemented in almost every aspect of our lifestyles and commercial enterprise functions where innovators and innovation are already changing the world in numerous ways and it goes beyond imagination as to where these technological advances can take us. Design Thinking is at the center of the digital transformation journey with a key focus on delivering superlative customer experience through emerging technology solutions which empower organizations to improve engagement and productiveness in order to drive future trends while addressing current challenges in the marketplace.

\section{FUELING THE FUTURE}

It is crucial for any business leader to determine where the opportunity lies and bridge the gap between what is the innovative idea that can fill the gap to the organization's benefit and how does that idea work on the market? If this is not implemented on time, it will never be an innovation. Across industries, regardless of company size or vertical, design thinking which really serves as a bridge between consumers and businesses, effectively empathizes the journey of innovative ideas quickly and accelerates the organizational efficiency by generating the most creative and valuable solutions that help them achieve an increased return on investment. "Falon Fatemi" founder and CEO of "Node - A global leader in AI platform solutions" describes in her article future of sales how design thinking is fueling up the sales across various industry sectors bringing in more revenue creating high business value. Organizations are already seeing significant potential in numerous ways to lead, manage, build and innovate using Design Thinking. "Roger Martin" in his book "The Design of Business - Why Design Thinking is the Next Competitive Advantage" emphasizes how creative thinking opens the door to innovation.

"Design-thinking firms stand apart in their willingness to engage in the task of continuously redesigning their business to create advances in both innovation and efficiency the combination that produces the most powerful competitive edge" - Roger Martin.

Moreover, we have entered the "Invention Age" and already have revolutionary technological advances such as Edge Computing, 5 G Network, Augmented Reality, Deep Learning and so on that are redefining industry sectors, generating various opportunities and transforming human lives. In his article "Stefan Link," explains how management portfolios such as Product, Business, Project Management, and so on can be revolutionized by applying the principles of design thinking which has the potential to innovate the business value for their organization. Furthermore, some of the world's leading companies such as IBM, Accenture, HCL Technologies, Apple Inc, Walmart, and so on are moving radically towards successful transformations with the design thinking approach.

Advancements in technology have dramatically changed the retail landscape over a period of time. With consumer demands increasing day by day, the retail industry is transforming business models by offering greater adaptability, connecting more channels and delivering personalized services to customers in order to enhance their shopping experience. An article by author Jeff Wells in grocerydive explains how to rethink about their selling models by embracing design thinking as an essential component of the operations to integrate customer needs, technology feasibilities and business success criteria.

Another industry with groundbreaking benefits is the education sector, where technology has played a pivotal role in the advancement of learning and teaching, with a key focus on student engagement. Design Thinking has great ability to generate new opportunities and radically changing the current education frameworks by providing enhanced techniques and procedures which empower students to understand better and eventually allowing them to imagine in multi-dimensions, giving a 360-degree view like educational experience. A recent study conducted by "Stanford Graduate School of Education" as described in an article on Fastcompany reveals some ground-breaking results on the performance of students 
when design thinking strategies are implemented across their everyday learning procedures, which tends to increase the problem solving skills of students making learning a more interactive journey with the active participation of students and professors.

We are already in a race and race is against time where technology innovation continues to evolve at the speed of light. Be it any industry sector like Education, Healthcare, Retail, Automotive, Travel etc. One thing is clear, the future looks splendid with design thinking approach which has the ability to generate high value to any organization by bringing in more and more breakthrough advancements helping enterprises to maximize the innovation in the journey of digital transformation.

\section{REFERENCES}

[1] Rafiq, Elmansy. (2016, April 7). Design Thinking Case Study: Innovation at Apple. Retrieved from https://www.designorate.com/design-thinking-case-study-innovation-atapple/

[2] http://fortune.com. Fortune. Retrieved May 7, 2019, from http://fortune.com/2017/02/15/airbnb-profits/

[3] How Design Thinking Transformed Airbnb from a Failing Startup to a Billion Dollar Business. Retrieved May 7, 2019, from https://firstround.com/review/How-design-thinking-transformed-Airbnbfrom-failing-startup-to-billion-dollar-business/

[4] Frank Van De Ven. (2017, November 16). What we can learn from Disney's artists for our design process. Retrieved from https://medium.com/@ frankvandeven/what-we-can-learn-from-disneysartists-for-our-design-process-1900c27acf7b

[5] Essig, T. (2018, May 2). Off to New Horizons with Design Thinking. Retrieved from https://medium.com/sap-innovation-spotlight/off-tonew-horizons-with-design-thinking-802f3028e9ee

[6] Innovation By Design Thinking:Netflix. TCU DESIGN THINKING. $\begin{array}{llll}\text { Retrieved } & \text { May } & 7, & 2019,\end{array}$ https://tcudesignthinking.wordpress.com/2017/05/03/innovation-bydesign-thinkingnetflix/

[7] Sloan, M., \& Management, of. (1970, January 1). Design Thinking Explained | MIT Sloan. MIT Sloan. Retrieved May 7, 2019, from https://mitsloan.mit.edu/ideas-made-to-matter/design-thinking-explained

[8] Useem, J. (2019, February 4). Why Ford Hired A Furniture Maker As CEO. The Atlantic. Retrieved May 7, 2019, from https://www.theatlantic.com/magazine/archive/2019/03/ford-ceo-jimhackett-ux-design-thinking/580438/

[9] https://medium.com/@brookecreef. (2018, March 1). Design Thinking and Design Sprints: How We Use Both at The Home Depot. Medium. Retrieved May 8, 2019, from https://medium.com/@brookecreef/designthinking-and-design-sprints-how-we-use-both-at-the-home-depot9 efc $2278 \mathrm{~d} 54 \mathrm{~d}$

[10] Montagner. Alberto, Angelika Reich, Hortensa de la Boutetiere, Cristy Chopra, Carolyn Dewar, Julie Goran, Michael Krusi. (2018, October 1). Unlocking Success In Digital Transformations. McKinsey \& Company. Retrieved May 20, 2019, from https://www.mckinsey.com/businessfunctions/organization/our-insights/unlocking-success-in-digitaltransformations

[11] 2019, January 1). From Design Thinking To Creative Confidence. IDEO U. Retrieved May 8, 2019, from https://www.ideou.com/blogs/inspiration/from-design-thinking-tocreative-confidence.

[12] Natalie, Mortimer. How PepsiCo Is Leveraging Design Thinking To Build Its Brands For 'future Societies'. The Drum. Retrieved May 8 , 2019, from https://www.thedrum.com/news/2015/09/04/how-pepsicoleveraging-design-thinking-build-its-brands-future-societies.
[13] Kirsner, Scott. (2017, August 18). How Delta Air Lines Is Prioritizing Innovation in An Operational Environment. Innovation Leader. Retrieved May 8, 2019, from https://www.innovationleader.com/deltaair-lines-innovation-operational-culture/

[14] Fatemi, F. (2019, January 15). Why Design Thinking Is the Future of Sales. Forbes. Retrieved May 8, 2019, from https://www.forbes.com/sites/falonfatemi/2019/01/15/why-designthinking-is-the-future-of-sales/\#1a2a03d84683

[15] Jarfas, Z. (2018, January 7). How Design Thinking Revived Adidas GLOBIS Insights. GLOBIS Insights. Retrieved May 7, 2019, from https://e.globis.jp/tech-innovation/how-design-thinking-revived-adidas/

[16] Martin, Roger L. (2009). The design of business. Boston, Mass: Harvard Business Press.

[17] Schwab, K. (2019, May 1). A Controversial Design Strategy Is Helping Sixth Graders Do Better In School. Fast Company. Retrieved May 11, 2019, from https://www.fastcompany.com/90341469/a-controversialdesign-strategy-is-helping-sixth-graders-do-better-in-school

[18] Lamey, D. (2018, January 5). Past, Present And Future: The Evolution Of Technology. DiscoverTec. Retrieved May 17, 2019, from https://www.discovertec.com/blog/evolution-of-technology

[19] Burke, Kenneth. (2016, May 18). How Many Texts Do People Send Every Day (2018)?. Text Request. Retrieved May 19, 2019, from https://www.textrequest.com/blog/how-many-texts-people-send-perday/

[20] (2019, May 1). Internet Growth Statistics 1995 To 2019 - The Global Village Online. Miniwatts Marketing Group. Retrieved May 20, 2019, from https://www.internetworldstats.com/emarketing.htm

[21] (2017, February 23). Industrial Revolutions: The 4 Main Revolutions In The Industrial World. Sentryo. Retrieved May 17, 2019, from https://www.sentryo.net/the-4-industrial-revolutions/

[22] Rifkin, J. (2012, March 3). The Third Industrial Revolution: How The Internet, Green Electricity, And 3-D Printing Are Ushering In A Sustainable Era Of Distributed Capitalism | The World Financial Review | Empowering Communication Globally. The World Financial Review. Retrieved May 18, 2019, from https://www.worldfinancialreview.com/the-third-industrial-revolutionhow-the-internet-green-electricity-and-3-d-printing-are-ushering-in-asustainable-era-of-distributed-capitalism/

[23] (n.d.). 1948. Retrieved May 17, 2019, from http://www.tvhistory.tv/1946-1949.htm

[24] Waniata, R. (2019, February 25). Need More Contrast In Your Life? Here's What You Need To Know About HDR TVs. Digital Trends. Retrieved May 17, 2019, from https://www.digitaltrends.com/hometheater/what-is-hdr-tv/

[25] Dyroff, C. (2018, July 25). Here's How Much Cellphones Have Actually Changed Over the Years. INSIDER. Retrieved May 17, 2019, from https://www.insider.com/the-history-of-the-cellphone-2018-7

[26] , C. (2019, May 18). Leonardo Da Vinci - Wikipedia. Wikipedia. Retrieved May $\quad 17, \quad 2019, \quad$ from https://en.wikipedia.org/wiki/Leonardo_da_Vinci

[27] Schulze, E. (2019, January 17). Everything You Need To Know About The Fourth Industrial Revolution. CNBC.com. Retrieved May 18, 2019, from https://www.cnbc.com/2019/01/16/fourth-industrial-revolutionexplained-davos-2019.html

[28] Markets, R. (2019, April 1). Digital Transformation Market By Technology (Cloud Computing, Big Data \& Analytics, Mobility/Social Media, Cybersecurity, Artificial Intelligence), Deployment Type, Business Function, Vertical (Retail, Education), Region - Globa Forecast To 2023. Research And Markets Ltd 2019. Retrieved May 20, 2019 ,

https://www.researchandmarkets.com/reports/4763835/digital-

transformation-market-by-

technology?utm_source=CI\&utm_medium=PressRelease\&utm_code=w mmp2j\&utm_campaign $=1236806+$

+Global+Digital+Transformation+Market+Forecast+to+2023++Digitalizing+Organizational+Business+Functions+to+Serve+Changing +Customer+Preferences+and+Enhance+Operational+Efficiency\&utm_e $\mathrm{xec}=\mathrm{chdo} 54 \mathrm{prd}$

[29] , C. (2017, October 31). Digital Transformation: 5 Examples Of Organizations That Excel. Digital Marketing Institute. Retrieved May 20, 2019, from https://digitalmarketinginstitute.com/en-us/blog/01-1117-digital-transformation-5-examples-of-organizations-that-excel 
[30] Woodford, Chris. (2019, March 19). History Of Invention: A Science And Technology Timeline. Explain That Stuff. Retrieved May 18, 2019, from https://www.explainthatstuff.com/timeline.html

[31] Link, stefan. (2017, December 15). Project Management 3.0-Why Design Thinking Is The Next-Gen. Medium. Retrieved May 9, 2019, from https://medium.com/swlh/project-management-3-0-why-designthinking-is-the-next-gen-5be78e509103

[32] This Is The Invention Age I 5g Innovation | Qualcomm. Qualcomm. Retrieved May 9, 2019, from https://www.qualcomm.com/invention-age

[33] Wells, J. (2019, May 10). Pardon the Disruption: Design Thinking And The Supermarket Of The Future. Grocery Dive. Retrieved May 11, 2019, from https://www.grocerydive.com/news/pardon-the-disruptiondesign-thinking-and-the-supermarket-of-the-future/554558/

[34] vale, R. (2016, July 21). Second Industrial Revolution: The Technological Revolution. Richmond Vale Academy. Retrieved May 17 2019, from https://richmondvale.org/en/blog/second-industrialrevolution-the-technological-revolution

[35] Rosin, Tamara. (2018, March 26). Digital Transformation Decoded: The CEO's Playbook. WalkMe Blog. Retrieved May 20, 2019, from https://blog.walkme.com/digital-transformationdecoded $/$ ?para $1=$ SMQ $\& \mathrm{t}=20$ 